Original Article

\title{
Comparison of whole-body vibration exercise and plyometric exercise to improve isokinetic muscular strength, jumping performance and balance of female volleyball players
}

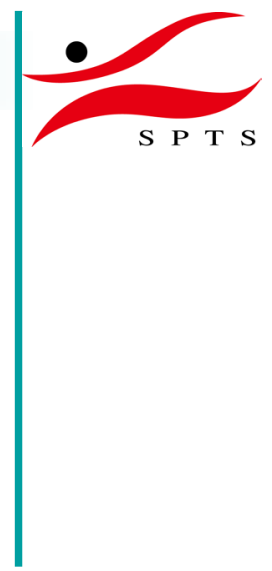

\author{
Yong-Youn Kim, PT, $\mathrm{PhD}^{1)}$, Si-Eun PARK, PT, $\mathrm{PhD}^{2)^{*}}$ \\ 1) Department of Physical Therapy, Dongnam Health University, Republic of Korea \\ 2) Department of Physical Therapy, Pohang College: 60 Sindeok-ro, Heunghae-eup, Buk-gu, Pohang-si \\ 791-711, Republic of Korea
}

\begin{abstract}
Purpose] The purpose of this study was to assess the effect of whole-body vibration exercise and plyometric exercise on female volleyball players. [Subjects and Methods] Subjects were randomly allocated to two exercise groups (whole-body vibration exercise group and plyometric exercise group). The exercise was conducted three times each week for 8 weeks. Isokinetic muscular strength, jumping performance, and balance were measured before starting the exercise and after finishing the 8 weeks of exercise. [Results] Measurements of isokinetic muscular strength revealed that the whole-body vibration exercise group showed significant increase after the exercise. However, the plyometric exercise group had no significant increase in lumbar flexion, extension, and knee flexion. Measurements of vertical jumping revealed that, the whole-body vibration exercise group had no significant increase after the exercise. However, the plyometric exercise group showed significant increase. Measurements of balance revealed that, the whole-body vibration exercise group showed significant increase. However, the plyometric exercise group showed no significant increase. [Conclusion] Although both whole-body vibration and plyometric exercises are effective intervention methods, the two methods have different effects on the improvement of isokinetic muscular strength, jumping performance, and balance of female volleyball players.

Key words : Female volleyball, Whole-body vibration, Plyometric exercise
\end{abstract}

(This article was submitted Jun. 8, 2016, and was accepted Jul. 21, 2016)

\section{INTRODUCTION}

Volleyball is recognized as one of the most popular sports in the world amongst men and women. It is an increasingly popular team sport ${ }^{1}$. In recent years, volleyball has witnessed remarkable technical progress, particularly in women's volleyball, with faster performance and evolving techniques accompanied by changes in the type ${ }^{2}$.

Most sports require various kinds of high and low muscle strength with fast or slow speed. Plyometric training is widely used as a method to develop explosive power capacity in sports that require jumping ability ${ }^{3)}$. Plyometric training is a type of muscle strength exercise that can improve basic physical strength. It has been extensively studied for its ability of improving exercise performance. It uses muscles' stretch reflexes and stretch-shortening cycles to develop lower extremity muscles ${ }^{4)}$. Therefore, plyometric training has been used a typical intervention method to enhance muscular function, and power ${ }^{5)}$. However, it might cause musculoskeletal injuries at landing phase ${ }^{6}$.

Therefore, various kinds of training methods have been implemented in order to improve the muscular power of sports players. Roelants et al. have reported that whole-body vibration exercise is an effective method for improving muscular

*Corresponding author. Si-Eun Park (E-mail: si-yaa@hanmail.net)

(C2016 The Society of Physical Therapy Science. Published by IPEC Inc.

This is an open-access article distributed under the terms of the Creative Commons Attribution Non-Commercial No Derivatives (by-nc-nd) License $<$ http://creativecommons.org/licenses/by-nc-nd/4.0/>. 
strength instead of resistance movements. In addition, it is a safe and effective exercise method for improving muscle strength ${ }^{7)}$. Whole-body vibration exercise provides an external stimulus for improving muscular strength, power, and performance in sports players ${ }^{8}$. Trovinen et al. have reported that whole-body vibration exercise offers a good chance of improving the jumping ability and the muscle strength of lower limbs in 56 healthy adults ${ }^{9}$. Therefore, it is expected that whole-body vibration exercise can enhance exercise capacity not only in athletes but also in the general population.

However, previous studies have not yet applied whole-body vibration exercises in female volleyball players. Therefore, in the present study, female volleyball players were divided into two groups: the whole-body vibration exercise (WBVE) group and the plyometric exercise (PME) group. The objective of this study was to examine the effects of the two exercises on isokinetic muscular strength, jumping performance, and balance ability of female volleyball players.

\section{SUBJECTS AND METHODS}

The present study was conducted among players who were registered and who played for female professional teams that belonged to the Korea Female Volleyball Federation. Study subjects were selected from those who had no orthopedic disease as disease could make it difficult for them to participate in regular games or training for regular games, and those who sufficiently understood the purpose and intent of this study. This study complied with the ethical principles of the Declaration of Helsinki. The subjects agreed to participate in the study after receiving explanations regarding its purpose and procedures. They all signed an informed consent statement before participation. The study protocol was approved by the local ethics committee of Yongin University (2-1040966-AB-N-01-20-1603-HSR-046).

Thirty subjects were initially selected and randomly divided into the whole-body vibration exercise group (WBVE group) or the plyometric exercise group (PME group). A total of 30 study subjects were selected initially. A total of 28 players were considered as final study subjects, after excluding two players who dropped out due to injuries. General characteristics of these subjects are summarized in (Table 1).

In the present study, subjects were divided into the WBVE group and PME group. The exercise was conducted for 50 min, three times per week, for a total of 8 weeks.

The WBVE group performed the exercises utilizing Natural waves. The exercise program consisted of warm-up exercises for 10 minutes, main exercises for 30 minutes, and cool-down exercises for 10 minutes. The 1 st and the 2 nd weeks were considered as the adaptation period. Three sets of exercises were performed. During the 3rd and the 4th weeks, four sets of exercise were performed. From the 5th week to the 8th week, four sets of exercise were performed with an increasing frequency of vibrations. The vibration frequency was set at $26 \mathrm{~Hz}$ during the 1 st and 2 nd week. From the 3rd week to the 8th week, the vibration frequency was set at $8 \mathrm{~Hz}$. Details of the whole body vibration exercise program is summarized in (Table 2).

The plyometric exercise was designed according to the method described by Jastrzebski et al ${ }^{10)}$. Before the intervention, subjects performed warm-up exercises for 20 minutes. After the exercise program began, each motion was limited to 10 times until the 2 nd week so that the subjects could adapt to the program. Thereafter, repeat count and sets of exercise were increased. The height of the box was increased from $20 \mathrm{~cm}$ to $30 \mathrm{~cm}$ after the fifth week. Details of the plyometric exercise program is summarized in (Table 3).

To assess muscular strength, isokinetic muscle strengths of the lumbar and knee joints were measured using a Humac (CSMI, USA). Subjects were instructed to perform flexion and extension exercises. Each subject practiced the exercises three times and took rest for three minutes before the measurement. Jumping performance was measured using digital jump meters (Takei, Japan). The vertical jump height with simultaneous explosive power in both legs was measured in units of $0.1 \mathrm{~cm}$ using measuring sensors. Jumping was performed a total of three times. The most excellent value was used as the measured value. Romberg's test was conducted to examine balance ability. Each subject was instructed to stand with the hip joint and knee joint flexed to $90^{\circ}$ with eyes closed and both hands placed on the waist. The measurement was conducted three times repeatedly. The average value was used as the measured value.

For data processing, SPSS 20.0 version for Windows software was used. Descriptive statistics were processed using the general characteristics of the subjects. Analysis of variance (ANOVA) was used to evaluate the changes in muscle strength, jumping ability, and balance. The significance level was set at $\mathrm{p}<0.05$.

\section{RESULTS}

Female volleyball players were divided into the WBVE group and the PME group. With respect to measurements of isokinetic muscular strength, the WBVE group showed significant increase in isokinetic muscular strength $(\mathrm{p}<0.05)$. The PME group showed no significant increase in the lumbar flexion and extension and knee flexion ( $p>0.05)$. However, muscle strength of the knee extension was significantly increased in the PME group $(p<0.05)$ (Table 4$)$.

With respect to the measurement of vertical jumping, the WBVE group showed no significant increased in vertical jump $(p>0.05)$. However, the PME group showed a significant increase in vertical jump $(p<0.05)$. With respect to the measurement of Romberg's test, the WBVE group showed a significant increase in the score of the Romberg's test $(\mathrm{p}<0.05)$. However, the PME group showed no significant increase in the score of the Romberg's test ( $p>0.05)$ (Table 5). 
Table 1. General characteristics of subjects

\begin{tabular}{lcc}
\hline & WBVE group & PME group \\
\hline Age (years) & $23.2 \pm 2.4$ & $23.5 \pm 4.2$ \\
Height $(\mathrm{cm})$ & $176.7 \pm 6.5$ & $178.3 \pm 6.5$ \\
Weight $(\mathrm{kg})$ & $70.3 \pm 8.2$ & $70.2 \pm 8.2$ \\
Body fat $(\%)$ & $22.9 \pm 3.83$ & $23.2 \pm 4.5$ \\
\hline
\end{tabular}

WBVE group: whole-body vibration exercise group; PME group: plyometric exercise group Mean \pm SD
Table 2. Whole-body vibration exercise program

\begin{tabular}{lccc}
\hline & $1-2$ week & 3-4 week & 5-8 week \\
\hline Training & Stretching & Stretching & Stretching \\
program & Squat & Squat & Squat \\
position & Lunge & Lunge & Lunge \\
& (front, side) & (front, side) & (front, side) \\
& One legged & One legged & One legged \\
& Standing & Standing & Standing \\
& Stretching & Stretching & Stretching \\
Frequency $(\mathrm{Hz})$ & 26 & 8 & 8 \\
Time $(\mathrm{min})$ & 50 & 50 & 50 \\
\hline
\end{tabular}

Table 3. Plyometric exercise program

\begin{tabular}{|c|c|c|c|c|c|c|c|c|c|}
\hline \multirow[b]{2}{*}{ Exercise type } & \multicolumn{3}{|c|}{$1-2$ week } & \multicolumn{3}{|c|}{ 3-4 week } & \multicolumn{3}{|c|}{ 5-8 week } \\
\hline & $\begin{array}{l}\text { Rep. } \times \\
\text { Series }\end{array}$ & $\begin{array}{l}\text { Sum of } \\
\text { jumps }\end{array}$ & $\begin{array}{c}\text { Height } \\
(\mathrm{cm})\end{array}$ & $\begin{array}{l}\text { Rep. } \times \\
\text { Series }\end{array}$ & $\begin{array}{l}\text { Sum of } \\
\text { jumps }\end{array}$ & $\begin{array}{l}\text { Height } \\
(\mathrm{cm})\end{array}$ & $\begin{array}{l}\text { Rep. } \times \\
\text { Series }\end{array}$ & $\begin{array}{l}\text { Sum of } \\
\text { jumps }\end{array}$ & $\begin{array}{c}\text { Height } \\
(\mathrm{cm})\end{array}$ \\
\hline Double-legs leap on the spot & $10 \times 2$ & 20 & - & - & - & - & - & - & - \\
\hline Forward single-leg leap & $10 \times 4$ & 40 & - & - & - & - & - & - & - \\
\hline Double-leg vertical jump on the spot & $1 \times 4$ & 40 & - & $1 \times 4$ & 48 & - & $12 \times 4$ & 48 & - \\
\hline Double-leg jump over a hurdle & $1 \times 4$ & 40 & 20 & $1 \times 4$ & 48 & 20 & $12 \times 4$ & 48 & 30 \\
\hline Squat leap (frog leap) & $4 \times 4$ & 16 & - & $7 \times 4$ & 28 & - & $7 \times 4$ & 28 & - \\
\hline Double-leg vertical jump from the squat jumps & - & - & - & $6 \times 5$ & 30 & - & $6 \times 5$ & 30 & - \\
\hline Approach run followed by a single-leg and vertical jump & - & - & - & $6 \times 4$ & 24 & 20 & $6 \times 4$ & 24 & 30 \\
\hline
\end{tabular}

Rep: repetition

Table 4. Measurement of isokinetic muscular strength

\begin{tabular}{llcc}
\hline & & Pre-test & Post-test \\
\hline \multirow{6}{*}{ WBVE group } & Lumbar flex (Nm) & $112.0 \pm 17.2$ & $129.4 \pm 15.1^{*}$ \\
& Lumbar ext (Nm) & $197.6 \pm 41.8$ & $225.1 \pm 31.4^{*}$ \\
& Right knee flex (nm) & $72.3 \pm 21.8$ & $81.5 \pm 17.9^{*}$ \\
& Right knee ext (nm) & $142.3 \pm 32.2$ & $184.2 \pm 39.7^{*}$ \\
& Left knee flex (nm) & $73.6 \pm 22.5$ & $84.7 \pm 19.7^{*}$ \\
& Left knee ext (nm) & $153.1 \pm 32.0$ & $189.8 \pm 36.7^{*}$ \\
& Lumbar flex (nm) & $101.9 \pm 15.3$ & $102.1 \pm 18.7$ \\
& Lumbar ext (nm) group & $191.3 \pm 38.9$ & $185.2 \pm 36.8$ \\
& Right knee flex (nm) & $64.0 \pm 8.7$ & $65.6 \pm 10.3$ \\
& Right knee ext (nm) & $137.0 \pm 22.4$ & $148.5 \pm 16.5^{*}$ \\
& Left knee flex (nm) & $61.3 \pm 8.1$ & $62.8 \pm 13.4$ \\
& Left knee ext (nm) & $134.9 \pm 23.0$ & $149.1 \pm 14.2^{*}$ \\
\hline
\end{tabular}

Values are mean $\pm \mathrm{SD}$.

WBVE group: whole-body vibration exercise group; PME group: plyometric exercise group; flex: flexion; ext: extension

*Significant difference between before and after the intervention

\section{DISCUSSION}

The purpose of all sports training is to maximize the physical and mental elements required to perform exercise or play games $^{4}$. Plyometric exercise has been a typical intervention method for enhancing the muscle power ${ }^{8}$. However, plyometric training requires careful attention because it requires high level of physical strength. It involves high intensity exercises. Therefore, it is associated with high risk of injuries ${ }^{11}$. Whole-body vibration exercise is a stable exercise method as it reduces 
Table 5. Measurement of vertical jump and Romberg test

\begin{tabular}{llll}
\hline & & \multicolumn{1}{c}{ Pre-test } & Post-test \\
\hline \multirow{3}{*}{ WBVE group } & Vertical jump $(\mathrm{cm})$ & $35.0 \pm 4.5$ & $37.9 \pm 6.4$ \\
& Right Rom test $(\mathrm{sec})$ & $23.8 \pm 9.1$ & $35.4 \pm 18.8^{*}$ \\
& Left Rom test $(\mathrm{sec})$ & $22.4 \pm 15.9$ & $38.1 \pm 16.7^{* *}$ \\
\multirow{3}{*}{ PME group } & Vertical jump $(\mathrm{cm})$ & $36.0 \pm 3.9$ & $41.2 \pm 43.9^{*}$ \\
& Right Rom test $(\mathrm{sec})$ & $24.5 \pm 11.7$ & $29.5 \pm 18.0$ \\
& Left Rom test $(\mathrm{sec})$ & $25.3 \pm 15.1$ & $31.0 \pm 17.8$ \\
\hline
\end{tabular}

Values are mean \pm SD.

WBVE group: whole-body vibration exercise group; PME group: plyometric exercise group

*Significant difference between before and after the intervention

physical stimulation while mechanical stimuli are applied to the muscles ${ }^{12)}$. Therefore, the present study examined the effect of whole-body vibration exercise versus plyometric exercise on female volleyball players.

With respect to the measurement of isokinetic muscular strength, the WBVE group showed significant increase in lumbar flexion and extension, and knee flexion and extension $(\mathrm{p}<0.05)$. Rees et al. have reported that vibration training is effective in improving the muscle strength of lower extremities ${ }^{13}$. Kim et al. have also reported that vibration exercises can stimulate the muscle spindles to recruit more motor units, thereby exerting greater power ${ }^{8)}$. This study also found that whole-body vibration activated proprioceptor (muscle spindle) and positively affected muscle strength ability.

In contrast, the PME group only had significant increase in knee extension $(p<0.05)$, but not in lumbar flexion and extension, or knee flexion ( $p>0.05$ ). Plyometric exercises are considered to have positive effects on the muscular strength of the extensor muscles of the lower limb rather than on the flexor muscles. Vertical jump was increased in the PME group ( $p<0.05$ ). The strengthening of the extensor muscles of the lower limb is considered to have positive effect on jumping ability. Park has reported that plyometric exercises can improve jumping ability through instantaneous exertion of elastic energy and stretch reflex of the lower limb with increased muscular strength ${ }^{14)}$. The reason for this occurrence might be due to the fact that plyometric exercise can increase the jumping performance.

The scores of Romberg's test were significantly increased in the WBVE group $(p<0.05)$. Courtine et al. have reported that vibration exercise can improve the proprioceptive function ${ }^{15)}$. Proprioception maintains the stability and orientation of the body during static and dynamic movements ${ }^{16)}$. Therefore, whole-body vibration in this study appears to have stimulated the proprioceptors, resulting in a positive effect on balance. However, the PME group showed no significant increase in the scores of Romberg's test ( $\mathrm{p}>0.05)$, indicating that plyometric exercise alone does not have a positive effect on balance ability.

In the present study, the whole-body vibration exercise had positive effects on isokinetic muscular strength, and balance ability. However, it did not have positive effect on jumping performance. In contrast, the plyometric exercise had positive effects on jumping performance. However, it did not have positive effect on balance. Therefore, we conclude that, although both whole-body vibration exercise and plyometric exercise are effective interventions for female volleyball players, there is a difference in improvement of isokinetic muscular strength, jumping performance, and balance between the two types of exercise.

This study included a limited number of subjects. Therefore, future studies should be performed using a larger number of subjects. Nevertheless, our study demonstrated the importance of whole-body vibration exercise and plyometric exercise in female volleyball players. We hope that diverse training methods will be used to train female volleyball players based on the findings of this study.

\section{REFERENCES}

1) James LP, Kelly VG, Beckman EM: Injury risk management plan for volleyball athletes. Sports Med, 2014, 44: 1185-1195. [Medline] [CrossRef]

2) Morikita I, Kishi S, Mitani Y: Incidence, symptioms and diagnosis of jumper's knee and knee contusions in female college volleyball players. J Phys Ther Sci, 2009, 21: 121-127. [CrossRef]

3) Kim HY: Effects of plyometric training on ankle joint motion and jump performance. Korean J Sports Med, 2012, 30: 47-54. [CrossRef]

4) Park GD, Lee JC, Lee J: The effect of low extremity plyometric training on back muscle power of high school throwing event athletes. J Phys Ther Sci, 2014, 26: 161-164. [Medline] [CrossRef]

5) Chelly MS, Ghenem MA, Abid K, et al.: Effects of in-season short-term plyometric training program on leg power, jump- and sprint performance of soccer players. J Strength Cond Res, 2010, 24: 2670-2676. [Medline] [CrossRef]

6) Humphries BJ, Newton RU, Wilson GJ: The effect of a braking device in reducing the ground impact forces inherent in plyometric training. Int J Sports Med, 1995, 16: 129-133. [Medline] [CrossRef]

7) Roelants M, Delecluse C, Verschueren SM: Whole-body-vibration training increases knee-extension strength and speed of movement in older women. J Am 
Geriatr Soc, 2004, 52: 901-908. [Medline] [CrossRef]

8) Kim J, Park Y, Seo Y, et al.: The effects of whole-body vibration exercise on isokinetic muscular function of the knee and jump performance depending on squatting position. J Phys Ther Sci, 2016, 28: 159-161. [Medline] [CrossRef]

9) Torvinen S, Kannus P, Sievänen H, et al.: Effect of four-month vertical whole body vibration on performance and balance. Med Sci Sports Exerc, 2002, 34: 1523-1528. [Medline] [CrossRef]

10) Jastrzebski Z, Wnorowski K, Mikolajewski R, et al.: The effect of a 6-week polyometric training on ecplosive volley ball players. Balt J Health Phys Act, 2014, 6: 79-89.

11) Houghton LA, Dawson BT, Rubenson J: Effects of plyometric training on achilles tendon properties and shuttle running during a simulated cricket batting innings. J Strength Cond Res, 2013, 27: 1036-1046. [Medline] [CrossRef]

12) Cloak R, Nevill A, Wyon M: The acute effects of vibration training on balance and stability amongst soccer players. Eur J Sport Sci, 2016, 16: 20-26. [Medline] [CrossRef]

13) Rees SS, Murphy AJ, Watsford ML: Effects of whole body vibration on postural steadiness in an older population. J Sci Med Sport, 2009, 12: 440-444. [Medline] [CrossRef]

14) Park HC: Effects of plyometric training and isokinetic training on power, agility, isokinetic muscle strength and jump performance ability improvement. Korae University Rehabilitation Science Graduate School, a Master's degree, 2006.

15) Courtine G, De Nunzio AM, Schmid M, et al.: Stance- and locomotion-dependent processing of vibration-induced proprioceptive inflow from multiple muscles in humans. J Neurophysiol, 2007, 97: 772-779. [Medline] [CrossRef]

16) Şahin N, Bianco A, Patti A, et al.: Evaluation of knee joint proprioception and balance of young female volleyball players: a pilot study. J Phys Ther Sci, 2015, 27: 437-440. [Medline] [CrossRef] 